their timings have been questioned, especially in the context of same day discharge practices.

Methods Staff at the largest volume device implant centres in the UK as well as to a selection of other implant centres chosen on an ad hoc basis were surveyed. Responses were received from 31 centres. The aim of the study was to assess the range of post implant practice currently used in the UK relating to device procedures where a new lead was introduced.

Results A range of practices were described relating to the timing and use of both CXR and device checks. $35.5 \%$ of centres did not mandate a post procedure CXR. At these centres, the most common reasons for requiring a CXR were the type of access used and the suspicion of procedure complication.

Use of device checks once a patient had left theatre also varied. Most centres performed a full interrogation, however 4 used only a 12 lead ECG, one a magnet check and one required no further check other than that performed on the table at the end of the case.

Timings for the CXR and check were similar within a centre but differed significantly between centres. $65 \%$ of centres responded to indicate that both investigations could be performed after a wait of $4 \mathrm{~h}$ or less from the time of implant.

Same day discharge following bradycardia device implant was considered at $68 \%$ of centres and $55 \%$ of centres following ICD/CRT device procedures. A number of factors were said to be used to guide its suitability.

Routine echo optimisation of all CRT devices was only reported by $16 \%$ of centres.

Conclusion There is a broad range of different practice between UK centres, relating to both the timing and use of CXR and device checks. Although still carried out in a large number of centres, traditional next day checks are no longer the norm.

\section{TIMING OF CARDIAC RHYTHM MANAGEMENT DEVICE COMPLICATIONS: IS DAY CASE IMPLANTATION SAFE?}

${ }^{1}$ Katharine Nelson*, ${ }^{2}$ Sarah Welsh, ${ }^{1}$ Jonathon Batty, ${ }^{1}$ Stephen Lord. ${ }^{1}$ Freeman Hospital; ${ }^{2}$ Newcastle University; * Presenting Author

\subsection{6/heartjnl-2016-309890.53}

Introduction Cardiac rhythm management (CRM) device implantation is a common medical procedure, considered to be safe in the majority of patients. Potential complications include pneumothorax, lead displacement, haematoma, infection and other wound problems. Whilst traditionally involving an overnight stay, some centres offer day-case procedures to selected patients. We sought to determine the time from implantation to detection of device-related complications, and thereby infer the safety of day-case implantation.

Methods A prospective database of all patients receiving a new CRM device, system replacement or upgrade over a 1 year period was maintained and screened for complications. Where identified, all medical, nursing and pacing notes were reviewed in order to determine first possible identification of a device-related complication; by symptoms, nursing observations or clinical investigations. Complications presenting less than $4 \mathrm{~h}$ post procedure were assumed to have prevented potential same day discharge. Pneumothoraces, pericardial effusions and wound problems were considered significant if they were actively managed. Lead displacements were considered significant if the patient experienced symptoms, loss of pacing function if pacing dependent, or a defibrillator discharge. Same-day discharge was considered to be non-inferior to routine discharge if no significant complication of pacing presented between $4 \mathrm{~h}$ and the time of routine discharge.

Results 109 complications occurred in 104 patients out of 1419 undergoing device implantation between October 2013 and September 2014. Complication rates according to device are detailed in Table 1.

61 of $104(58.7 \%)$ patients would not have been triaged to day case implantation due to an urgent device indication and/ or scheduled upgrade or system replacement. 6 (5.5\%) complications presented before $4 \mathrm{~h}$ and so would have prevented early discharge. 22 presented after discharge the following day, our usual standard of care. 20 complications (5 pneumothoraces, 15 lead displacements) presented between 4 $\mathrm{h}$ and the time of discharge. One pneumothorax was managed with a chest drain having been identified on routine chest Xray without prior symptoms or signs. Of 15 patients with lead displacement $4(26.7 \%)$ experienced symptoms of twitch or palpitations, the remainder being identified on routine device interrogation the following day. 13 leads were repositioned or replaced and 2 were deactivated. There were no

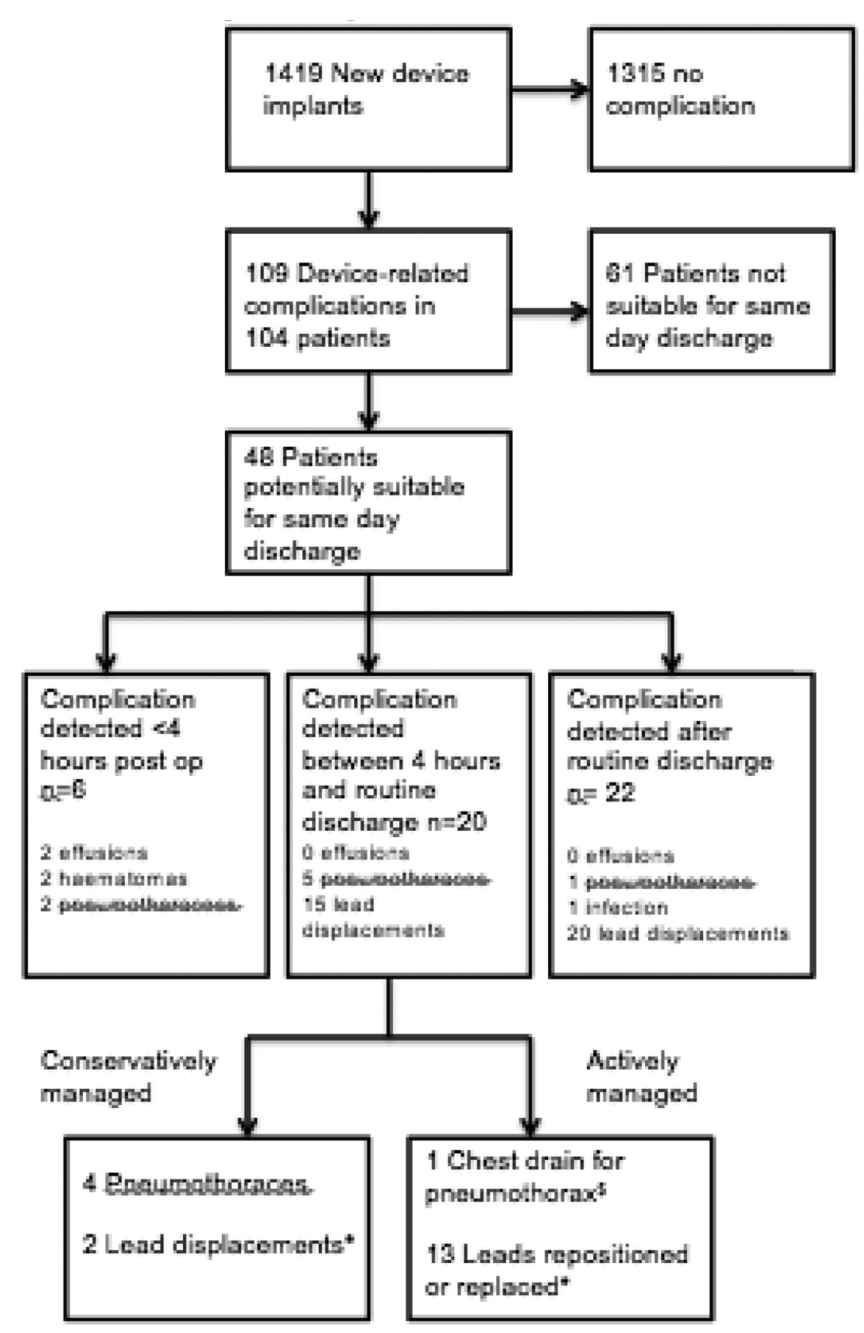

Abstract 53 Figure 1 Device-related complications in patients suitable for day-case implantation 
Abstract 53 Table 1 Device implantation according to device

\begin{tabular}{|c|c|c|c|c|c|c|}
\hline Device & PPM & ICD & CRT-P & CRT-D & $\begin{array}{l}\text { Device } \\
\text { upgrade }\end{array}$ & Total \\
\hline Number implanted & 705 & 339 & 129 & 246 & 66 & 1419 \\
\hline Pneumothorax (\%) & $13(1.8)$ & $4(1.25)$ & $2(1.6)$ & 0 & 0 & $19(1.3)$ \\
\hline $\begin{array}{l}\text { Lead displacement } \\
\text { Patients (\%) } \\
\text { RA } \\
\text { RV } \\
\text { LV }\end{array}$ & $\begin{array}{l}31(4.4) \\
13^{*}(1.8) \\
22^{-}(3.1) \\
0\end{array}$ & $\begin{array}{l}20(5.9)^{\text {it }} \\
8(2.3) \\
13(3.8)\end{array}$ & $\begin{array}{l}2(1.6) \\
0 \\
0 \\
2(1.6) \\
\end{array}$ & $\begin{array}{l}13(5.3) \\
4(1.6) \\
2(0.8) \\
7(2.8) \\
\end{array}$ & $\begin{array}{l}3(4.5) \\
1(1.5) \\
0 \\
2(3) \\
\end{array}$ & $\begin{array}{l}68(4.8) \\
26(1.8) \\
37(2.6) \\
11(0.8)\end{array}$ \\
\hline $\begin{array}{l}\text { Wound problem } \\
\text { Haematoma (\%) } \\
\text { Infection (\%) } \\
\text { Painful pocket }(\%)\end{array}$ & $\begin{array}{l}3(0.4) \\
2(0.3) \\
1(0.1)\end{array}$ & $\begin{array}{l}1(0.3) \\
4^{4}(1.2) \\
2(0.6)\end{array}$ & $\begin{array}{l}0 \\
0 \\
0\end{array}$ & $\begin{array}{l}0 \\
1(0.4) \\
1(0.4)\end{array}$ & $\begin{array}{l}0 \\
1(1.5) \\
0\end{array}$ & $\begin{array}{l}4(0.3) \\
8(0.6) \\
4(0.3)\end{array}$ \\
\hline $\begin{array}{l}\text { Effusion } \\
\text { Conservatively } \\
\text { managed } \\
\text { Jamponade (requiring } \\
\text { drain) }\end{array}$ & $\begin{array}{l}4(0.6) \\
1(0.1)\end{array}$ & $\begin{array}{l}0 \\
0\end{array}$ & $\begin{array}{l}0 \\
0\end{array}$ & $\begin{array}{l}0 \\
0\end{array}$ & $\begin{array}{l}1(1.5) \\
0\end{array}$ & $\begin{array}{l}5(0.35) \\
1(0.07)\end{array}$ \\
\hline
\end{tabular}

\section{*One patient had RA lead reposition followed by RA lead replacement "One patient had RV lead reposition followed by RV lead replacement *One patient had both RA and RV lead displacement, both repositioned at the same procedure \$includes 2 post lead revision and 1 post new system post extraction}

bradyarrhythmias, loss of pacing function when pacing-dependent or inappropriate defibrillator shocks. The were no devicerelated deaths or complications requiring ITU level care.

Conclusion Same day discharge appears safe in an unselected population of patients undergoing elective primary implantation of a CRM device at a high-volume cardiothoracic unit. Procedural difficulties, symptoms or signs suggestive of a potential complication should prompt further evaluation, and all patients should undergo device interrogation and chest radiography prior to discharge.

\section{MEASURES OF ENDOTHELIAL DYSFUNCTION PREDICT RESPONSE TO CARDIAC RESYNCHRONISATION THERAPY}

${ }^{1}$ David Warriner*, ${ }^{2}$ Ryan Crapper, ${ }^{1}$ Patricia Lawford, ${ }^{3}$ Paul Sheridan. ${ }^{1}$ Sheffield University; ${ }^{2}$ Sheffield Teaching Hospitals; ${ }^{3}$ Chesterfield Royal Infirmary; ${ }^{*}$ Presenting Author

10.1136/heartjnl-2016-309890.54

Background Cardiac resynchronisation therapy (CRT) improves morbidity and mortality in heart failure (HF). Impaired endothelial function, as measured by flow mediated dilation (FMD) is associated with increased morbidity and mortality in heart failure (HF) and may help to differentiate responders from non-responders.

Methods FMD was measured at baseline and 12 months following CRT. The patient group were 94\% male, mean age 69 \pm 8 years, New York Heart Association (NYHA) functional class II-IV, QRSd $173 \pm 21 \mathrm{~ms}$ and had a left ventricular ejection fraction (LVEF) $26 \pm 8 \%$.

Results $70 \%$ of patients were found to have responded at 12 months. Responders had significant improvements in $\mathrm{VO}_{2}$ $(12.6 \pm 1.7$ to $14.7 \pm 1.5 \mathrm{ml} / \mathrm{kg} / \mathrm{min}, p<0.05)$, quality of life score $(43 \pm 23$ to $24 \pm 22, p<0.01)$, left ventricular end diastolic volume $(210 \pm 125 \mathrm{ml}$ to $173 \pm 125 \mathrm{ml}, p<$ $0.01)$, NT-proBNP $(2422 \pm 829 \mathrm{ml}$ to $1732 \pm 976 \mathrm{ml}, p<$ 0.01 and $6 \mathrm{~min}$ walk distance $(379 \pm 117 \mathrm{~m}$ at baseline to $418 \pm 105 \mathrm{~m}, p<0.05)$. Baseline FMD in responders was $2.9 \pm 1.9 \%$ and $7.4 \pm 3.73 \%$ in non-responders $(p<0.05)$. Conclusions This confirms that FMD identifies response to CRT, due to endothelium dependent mechanisms alone.

\section{EVALUATION OF POTENTIAL CLINICAL RESPONSE AND CARDIOVASCULAR OUTCOMES PREDICTORS IN A TERTIARY CARDIAC RESYNCHRONISATION THERAPY IMPLANTATION CENTRE}

Christopher McAloon*, Dominic Heining, Gavin Atherton, Benjamin Anderson Harpal Randeva, Paul O'Hare, Faizel Osman. University Hospital Coventry and Warwickshire; *Presenting Author

\subsection{6/heartjnl-2016-309890.55}

Background Cardiac Resynchronisation Therapy (CRT) is an effective treatment for dys-synchronous chronic heart failure $(\mathrm{CHF})$, however there is a significant non-response rate. Clinic predictors of response and cardiovascular outcome are often inconsistently reported. The aim of the study was to examine previously reported clinical predictors of response and cardiovascular outcomes in a heterogeneous CHF patients undergoing CRT implantation at a UK tertiary centre.

Methods A retrospective single-centre cohort study of all consecutive CRT implantations (147 (49.0\%) CRT-p; 153 (51.0\%) CRT-d) performed over 5 years (Jan 2009-Dec 2013). Implants had to meet eligibility criteria; successful implant, follow-up case records availability and clinical response determination. Clinical response was defined by three independent reviewers as a New York Heart Association classification symptom reduction $>1$ class or class I maintenance from pre- 